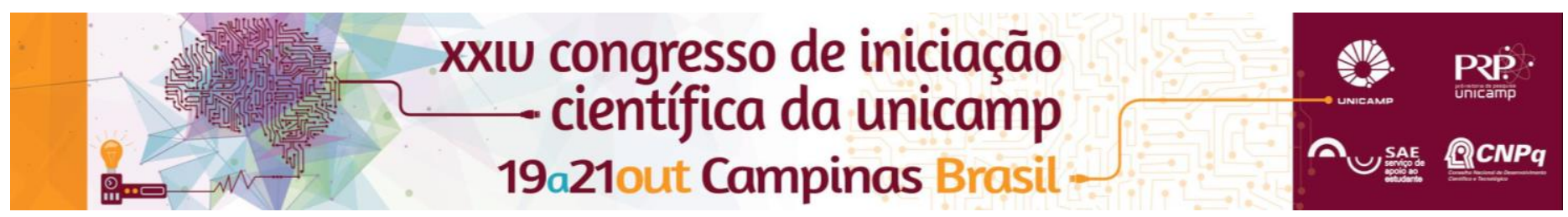

\title{
Efeito do uso prévio de dentifrícios contendo diferentes princípios ativos sobre o esmalte clareado e posteriormente manchado com vinho tinto.
}

\author{
Raíssa Garcia*, Waldemir F. Vieira-Junior, Jéssica D. Theobaldo, Flavio Henrique Baggio Aguiar, Glaúcia Maria \\ Bovi Amborsano, Débora Alves Nunes Leite Lima.
}

\begin{abstract}
Resumo
O efeito de dentifrícios que induzem a precipitação mineral no esmalte clareado é desconhecido. O objetivo do estudo foi avaliar os efeitos nas propriedades físicas e morfológicas do esmalte exposto a dentifrícios, clareamento e posteriormente submetido a um modelo de erosão/manchamento com vinho. Os resultados demonstraram que os dentifrícios protegem o esmalte contra a alteração de rugosidade que o tratamento clareador pode promover (vidro bioativo, fluoreto de estanho e arginina) e efeito anti-erosivo na exposição ao vinho (fluoreto de estanho). Em relação a suscetibilidade ao manchamento, o clareamento aumenta a incorporação de pigmentos, entretanto o dentifrício com quitosana diminuiu essa suscetibilidade (luminosidade). No esmalte não clareado os dentifrícios contendo arginina ou fluoreto de estanho aumentaram a sucetibilidade ao manchamento.
\end{abstract}

Palavras-chave:

clareamento, peróxido de hidrogênio,dentifrício

\section{Introdução}

Alguns princípios ativos presentes nos dentifrícios promovem precipitação/formação mineral no esmalte (Lombardini et al, 2014). Nesse sentido, uma vez que a rugosidade superficial está associada à deposição de pigmentos extrínsecos e ainda a mudanças que provocam alteração na reflectância da luz. O objetivo desse estudo foi avaliar os efeitos topográficos e cromáticos do esmalte exposto a dentifrícios, clareamento e posteriormente submetido a um modelo de erosão/manchamento com vinho.

\section{Resultados e Discussão}

Métodos: 120 blocos de esmalte/dentina bovinos foram imersos em slurry dos seguintes tratamentos $(n=12)$ : $G 1$ e G6 - saliva artificial/controle; G2 e G7 - Oral B® Pró-Saúde $\left(\mathrm{SF}-\mathrm{SnF}_{2}\right.$ ), G3 e G8 - Sensodyne ${ }^{\circledR}$ Repair \& Protect (NM Vidro bioativo), G4 e G9 - Colgate ${ }^{\circledR}$ Pró-Alivio (AR Arginina), G5 e G10 - Chitodent ${ }^{\circledR}$ (Chi - Quitosana). Após a exposição, 60 amostras foram clareadas com peróxido de hidrogênio $35 \%$ (G6-G10) e as outras 60 não (G1-G5). Posteriormente, todos os espécimes foram imersos em vinho tinto durante 6 horas $\left(37^{\circ} \mathrm{C}\right)$. Durante o experimento, as amostras foram armazenadas em saliva artificial. A morfologia foi avaliada pela análise da rugosidade $(\mathrm{Ra})$ e a cor por espectrofotometria de reflectância (CIE $L^{*} a^{*} b^{*}-\Delta E$ ) nos tempos: inicial (T1), pós-protocolo de dentifrício e/ou clareamento (T2) e pós-manchamento (T3). Os dados foram submetidos à ANOVA (Proc-Mixed) de medidas repetidas e teste de Tukey $(\alpha<0,05)$. Resultados: Ra - efeito nos fatores: dentifrício, clareamento, tempo e na interação entre eles. Nenhum dentifrício promoveu aumento de rugosidade $(p>0,05)$. O clareamento promoveu aumento da rugosidade $(p<0,05)$, entretanto a utilização dos dentifrícios SF, NM e PA protegeram o esmalte dessa alteração. Em T3, A Ra foi maior no no grupo controle clareado $(p<0,05)$. O SF não apresentou alteração de $\mathrm{Ra}$ após exposição ao vinho ( $p>0,05)$ nos grupos não clareados. Os resultados de $L^{*} e$ $b^{*}$ demonstraram efeito nos fatores: dentifrício, clareamento, tempo e na interação entre eles. Nenhum dentifrício interferiu na efetividade clareadora do peróxido de hidrogênio 35\%. Na ausência do clareamento em T3, os dentifrícios SF e PA apresentaram menores valores de $L^{*}$ $(p<0,05)$. Em T3, o grupo clareado apresentou valores $L^{*}, b^{*}$ e $\Delta E$ diferentes $(p<0,05)$ do controle não clareado. Em T2, Chi promoveu valores de $L^{*}$ maiores e estatisticamente diferentes do controle clareado $(p<0,05)$. Os resultados de $a^{*}$ demonstraram ausência de efeito nos fatores dentifrício e clareamento e efeito no fator tempo, com aumento dos valores de $a^{*}$ em todos os grupos em T3. A variação geral da cor $(\Delta E)$ demonstrou efeito no fator clareamento $e$ ausência de efeito no fator dentifrício (T1xT2). Entretanto, em T2xT3 foi verificado efeito para os fatores dentifrício, clareamento e para a interação entre esses dois fatores. $\mathrm{Na}$ ausência do clareamento, o PA promoveu maiores valores de $\Delta \mathrm{E}$ que foram diferentes estatisticamente do controle $(p<0,05)$. Os dentifrícios aqui avaliados possibilitam um aumento da biodisponibilidade de cálcio, fluoreto, fosfato e sódio, que são atraídos por estruturas carregadas negativamente, como o esmalte (Young et al.,1997). E a formação desses complexos demonstrou efeito e interação com o procedimento clareador (Vieira-Junior et al, 2016) e com a erosão/manchamento causada pelo vinho.

\section{Conclusões}

Os dentifrícios podem proteger o esmalte contra a alteração de rugosidade que o tratamento clareador pode promover (vidro bioativo, fluoreto de estanho e arginina); efeito antierosivo na exposição ao vinho (fluoreto de estanho); e podem ainda diminuir oo manchamento (quitosana) ou potencializar a incorporação de pigmentos (arginina e fluoreto de estanho).

\section{Agradecimentos}

Ao Pibic-Unicamp pela concessão da bolsa de iniciação científica.

Lombardini, M., Ceci, M., Colombo, M., Bianchi, S., \& Poggio, C (2014). Preventive effect of different toothpastes on enamel erosion: AFM and SEM studies. Scanning, 36(4), 401-410.

Young, A., Smistad, G., Karlsen, J., Rölla, G., \& Rykke, M. (1997). Zeta potentials of human enamel and hydroxyapatite as measured by the Coulter® DELSA 440. Advances in dental research, 11(4), 560-565.

Vieira-Junior, W. F., Lima, D. A. N. L., Tabchoury, C. P. M., Ambrosano, G. M. B., Aguiar, F. H. B., \& Lovadino, J. R. (2016). Effect of Toothpaste Application Prior to Dental Bleaching on Whitening Effectiveness and Enamel Properties. Operative dentistry, 41(1), E29E38. 